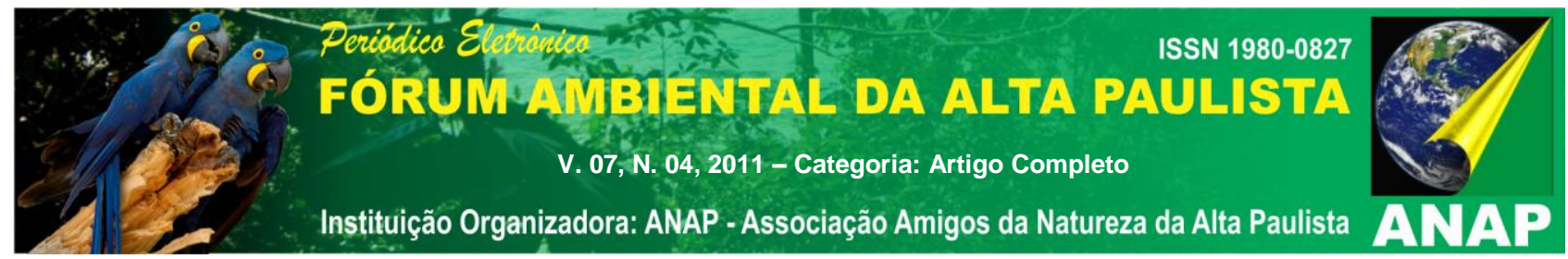

\title{
INDICADORES DE SUSTENTABILIDADE URBANA
}

\author{
Regina Célia Foschini ${ }^{1}$
}

RESUMO: Hoje as cidades encontram-se em trágica situação, como crescimento urbano desarticulado, resíduos urbanos, aumento de densidade populacional, degradação ambiental, etc. Partindo do conceito de desenvolvimento sustentável e das críticas sobre os desastrosos efeitos dos processos de urbanização ocorridos no planeta nos últimos trinta anos, iniciou-se a pesquisa fazendo um levantamento dos conceitos de indicadores e índices, e ao final, após utilizar a metodologia de forma dialética e comparativa, foi possível refletir sobre os critérios na escolha dos indicadores.

Palavras-chave: Indicadores. Sustentabilidade.Meio urbano.

\section{INTRODUÇÃO}

Segundo Kayano (apud ALMEIRA) "indicadores são ferramentas utilizadas pela comunidade, órgãos públicos e privados, para avaliar e monitorar as tendências de seu desenvolvimento, bem como sua eficiência e eficácia, definindo metas de melhoria".

Durante muitos anos os indicadores econômicos e financeiros foram usados como indicadores de qualidade de vida. No entanto, "as inquietações relativas às qualidades do ar, do solo, da água, às formas de apropriação desses e de outros recursos naturais bem como aos padrões de produção e consumo praticados pela sociedade atual, têm expandido a busca pela elaboração de indicadores que propiciem um banco de dados capaz de respaldar a formulação de políticas e ações urbanas. Um trabalho de intervenção integrada tem requerido a produção de informações tais que possibilitam o acompanhamento da realidade física e social por meio da avaliação de impactos e as suas conseqüências para o meio natural e particularmente para a vida humana nos centros urbanos" (SILVA, 2000). Assim, os indicadores de sustentabilidade surgem em

\footnotetext{
${ }^{1}$ Advogada, mestre em Engenharia Urbana pela Universidade Federal de São Carlos. E-mail: reginafos@yahoo.com.br
} 


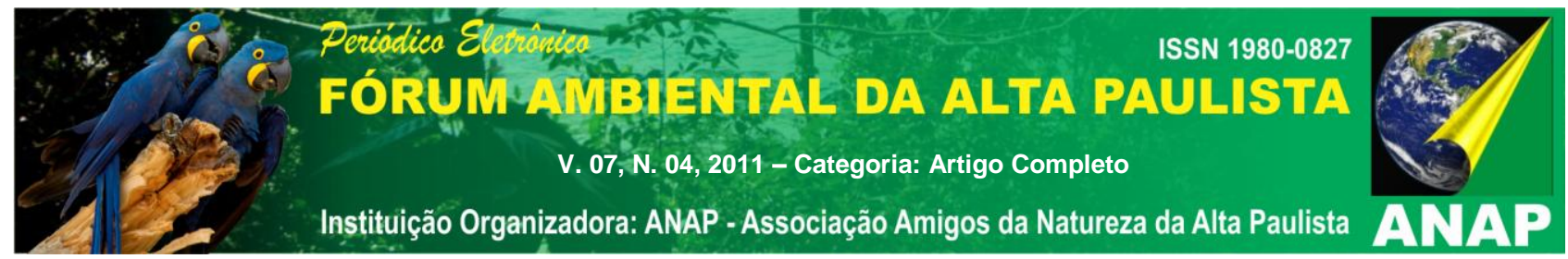

diversos países e tem por base as variáveis e os índices levantados de acordo com os objetos de preocupação dos governos.

Segundo a Agenda 21 (CNUMAD apud FIGUEIREDO, 2000), os indicadores de sustentabilidade servem para:

- Formação de uma base sólida para a tomada de decisões em todos os níveis: tendo como objetivos a coleta e avaliação de dados mais pertinentes e eficazes, em relação aos custos por meio de melhor identificação dos usuários, tanto no setor público quanto no privado, e de suas necessidades de informação nos planos local, nacional, regional e internacional;

- Desenvolver ou fortalecer os meios locais, provinciais, nacionais e internacionais: garantindo que a planificação do desenvolvimento sustentável em todos os setores se baseie em informações fidedigna, oportuna e utilizável;

- Tornar a informação pertinente acessível: na forma e no momento em que for requerida para facilitar o seu uso.

No entanto, há necessidade de se obter mais de um indicador para captar todos os aspectos importantes de uma situação. Como aduz Bossel (apud FIGUEIREDO, 2000): "um único indicador não consegue nunca contar toda a história".

Almeida (2003) ressalta que "para se obter bons indicadores deve-se tomar vários cuidados quanto a sua concepção, pois nem sempre a compreensão dos indicadores pela sociedade é clara e precisa, causando divergência em seus resultados".

\section{INDICADORES E ÍNDICES}

Indicador é considerado pelo Ocde (apud ALMEIDA, 2003) como "um parâmetro, ou um valor derivado de um parâmetro, que fornece as informações sobre um fenômeno". E Sustainable Seattle (apud FIGUEIREDO, 2000) define indicadores de sustentabilidade como "fragmentos de informações que salientam o que está acontecendo em um sistema mais amplo".

Já o conceito de índice, Almeida (2003) aduz que "consiste em um grupo de indicadores, promovendo uma síntese de dados em uma única expressão. $O$ índice busca sintetizar informações de um fenômeno ou conjunto de fenômenos, tornando a informação mais simplificada, sendo considerado também um indicador".

Granados \& Peterson (apud ALMEIDA, 2003; FIGUEIREDO, 2000) ressaltam que "uma das fraquezas dos índices é que os dados podem ser perdidos ou escondidos 


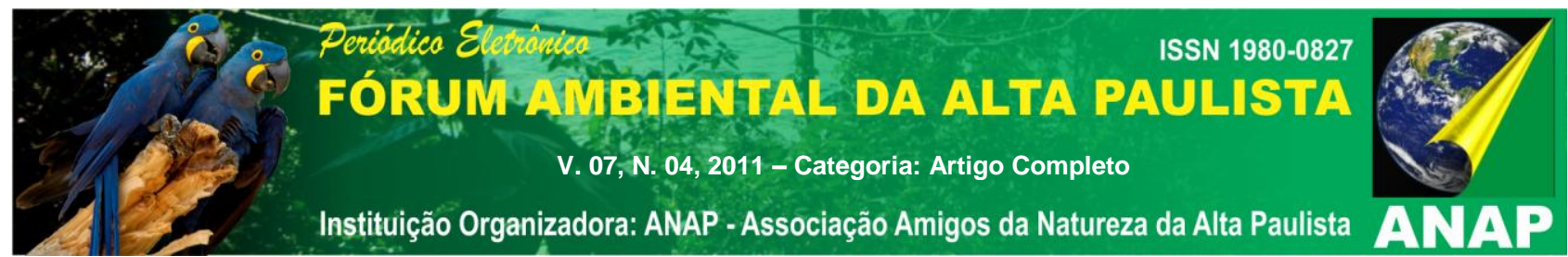

no processo de agregação. Além disso, diferentes cenários podem levar ao mesmo valor dos índices, correndo-se o risco de não conseguir identificar um problema de forma mais exata, dificultando sua correção".

Assim, o uso de indicadores está relacionado à necessidade de medição de um fenômeno, tanto para o simples conhecimento de uma realidade, quanto para tomada de decisões e monitoramento de sua evolução.

Para uma gestão ser eficiente e eficaz é preciso monitorar e analisar uma grande quantidade de fenômenos.

Figueiredo (2000) então explica que "a principal razão para se medir o desempenho de um sistema organizacional é apoiar seu processo de melhoria. Realizamse medições porque estas dirão qual a capacidade do sistema e o que pode ser esperado dele. Além disso, as medições fornecem feedback necessário para a avaliação de uma intervenção".

Entre os objetivos das medições, Silk \& Tuttle (apud FIGUEIREDO, 2000) citaram: controle, realização de previsões, análises de variações, estimativas de custos, planejamento, avaliação de pessoal, controle de qualidade, planejamento de ações, gerenciamento de projetos, análise e gerenciamento orçamentário, decisões sobre investimento, análise de custo e benefício, análise econômica, garantia de implementação de estratégias e motivação. Sendo, portanto, a medição e o uso de indicadores necessários em qualquer processo de gestão".

Assim, Alemanha (apud FIGUEIREDO, 2000) explica que "os indicadores de sustentabilidade, de forma geral, têm sido usados para aumentar a base de informação e comunicação do estado do ambiente para a sociedade e para os formuladores de políticas públicas; auxiliar na elaboração de políticas para as questões ambientais, sociais e econômicas e permitir a comparação entre diferentes regiões".

\section{CRITÉRIOS PARA ESCOLHA DE INDICADORES}

ALMEIDA (2003) explica que "para que se consiga criar um sistema de indicadores, é importante estabelecer critérios para alcançar o objetivo pretendido. 


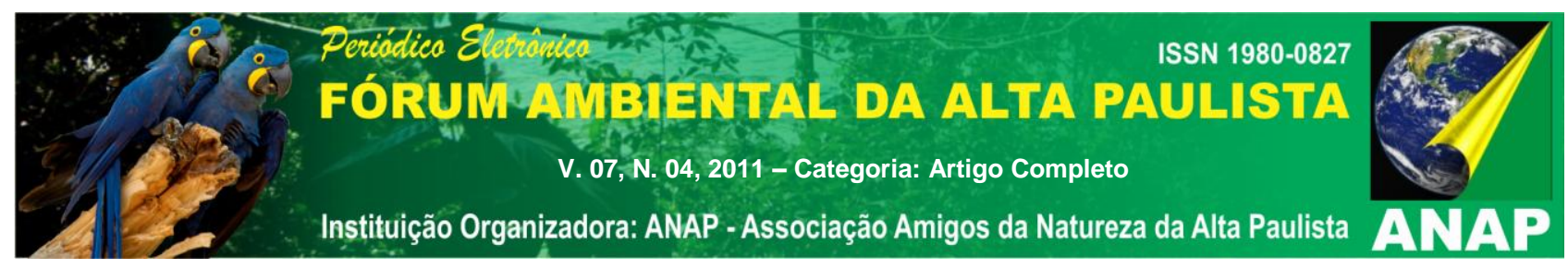

KAYANO (apud ALMEIDA, 2003) estabelece alguns critérios básicos para desenvolver indicadores, sendo:

- ter clareza nos dados;

- ter qualidade e precisão das informações;

- medir ao longo do tempo;

- estabelecer comparações com diferentes locais;

- estabelecer um padrão normativo;

- ser de fácil compreensão;

- ter validade e estabilidade;

- expressar características essenciais e mudanças esperadas;

- ter amplitude e diversidade;

- ser independente;

- ser confiável;

- ser de fácil obtenção.

Já Michell (apud ALMEIDA, 2003) desenvolveu uma estrutura metodológica para estabelecer indicadores de sustentabilidade, com s seguintes critérios:

- relevantes nos resultados pretendidos e cientificamente defensáveis;

- sensíveis a alterações de espaço e de grupos sociais;

- sensíveis a mudanças ao longo do tempo;

- apoiados em dados consistentes;

- compreensíveis, se for o caso, que tenham ressonância;

- mensuráveis;

- expressos de forma que faça sentido;

- identificação das metas e tendências que identifiquem uma evolução para uma sustentabilidade desejável.

E A Sustainable Seattle (apud ALMEIDA, 2003) propôs algumas características para a escolha de indicadores de sustentabilidade:

* fácil interpretação;

* mostrar as tendências através do tempo;

* compatibilidade com a escala espacial ao qual está aplicado;

* comparações com outras situações no tempo e no espaço;

* referência em um parâmetro acessível;

* contemplas as inter-relações dos fatores externos;

* relação de custos e benefícios;

* consideração de fatores humanos e ecológicos;

* dimensão ao longo do tempo.

Almeida (2003) ainda aduz que "os indicadores de sustentabilidade devem possuir duas características: devem ter abrangência espacial e, sobretudo temporal, de forma a serem estabelecidos em um espaço numa determinada época, mas podendo permanecer nas gerações futuras e em outras localidades com as mesmas características". 


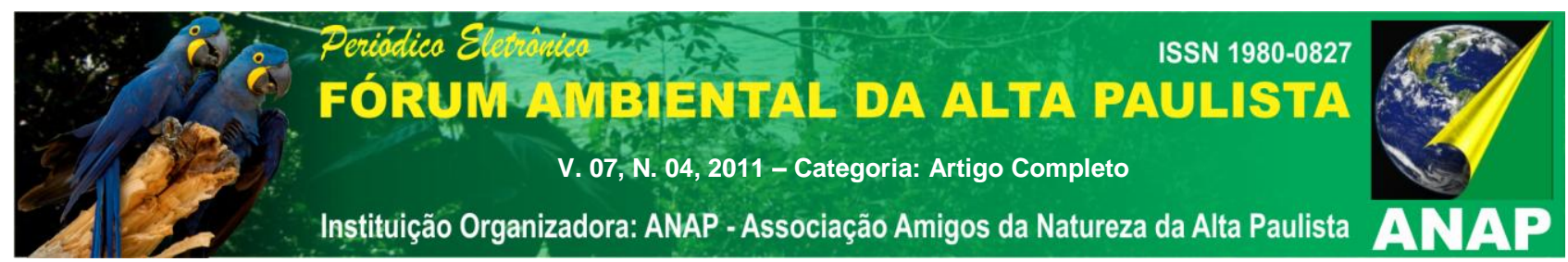

Segundo a Agência Federal de Meio Ambiente da República Federal da Alemanha (apud ALMEIDA, 2003), os indicadores de sustentabilidade foram divididos em quatro grupos:

1 - Indicador de força de ação: dizem respeito aos fatores causais, como performace do transporte ou consumo de energia e recursos.

2 - Indicadores de pressão: refletem a pressão que as atividades humanas exercem sobre o meio ambiente, como o nível de emissões de poluentes, a produção de resíduos e o uso da terra.

3 - Indicadores de estado: tentam medir as mudanças de estado do meio ambiente que resultam dos impactos do desenvolvimento, representam a qualidade do meio ambiente, por exemplo, qualidade dos corpos d'água.

4 - Indicadores de resposta: descrevem as respostas da sociedade à mudanças ocorridas, ou as atividades e estratégias adotadas para prevenir e remediar impactos negativos. Podem-se citar: aumento do serviço de coleta e tratamento de esgotos.

Assim, conclui-se que os países devem desenvolver sistemas de monitoramento e avaliação para atingir a sustentabilidade adotando indicadores que meçam as mudanças nas dimensões econômica, social e ambiental. Mas, muitas vezes, devido a complexidade dos assuntos que abordam, é necessário uma lista extensa de indicadores, tornando difícil o monitoramento. Então, Bossel (apud ALMEIDA, 2003) sugeriu alguns procedimentos para reduzir a quantidade de indicadores:

- agregação: utilizar o indicador mais agregado possível;

- condensação: utilizar o indicador que represente a última conseqüência de um determinado problema, sem considerar os indicadores e sistemas intermediários;

- estoque de elo mais fraco: dar referência aos componentes que podem representar uma real ameaça ao sistema;

- "cesta básica": se houver diferentes indicadores vinculados, pode-se considerar a criação de índices que ofereçam uma visão média da situação;

- "cesta mínima": se a satisfação de um aspecto depender do estado de cada um dos vários indicadores, pode-se escolher, como indicador representativo, aquele que possuir o pior resultado;

- indicador representativo: identificar a variável que ofereça uma informação confiável do desenvolvimento do sistema;

- avaliação subjetiva da viabilidade: se uma pequena quantidade de informações estiver disponível, deve-se fazer uma avaliação subjetiva e sumária do sistema. 


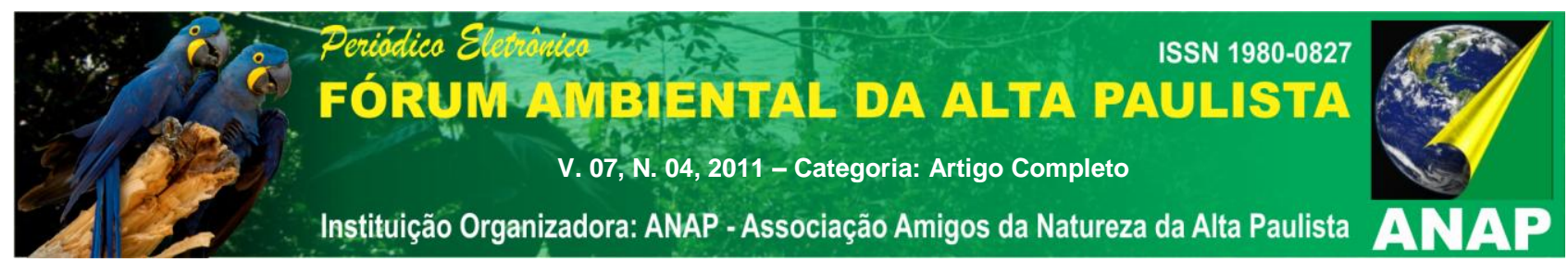

Para facilitar o processo de escolha de indicadores e tentar garantir que diferentes dimensões fossem consideradas, foram criados alguns modelos conceituais para organização dos indicadores.

Mas, pelo fato de muitas vezes os indicadores utilizados apresentar variáveis com a mesma finalidade, Milanez (apud ALMEIDA: 2003), após uma análise comparativa da escolha de indicadores, segundo vários autores, obteve uma lista com 14 critérios:

1-coerência com a localidade local: representar valores locais;

2-relevância: refletir algo que seja importante sobre o que se deseja medir;

3-clareza na comunicação: ser claro e simples, permitindo uma rápida compreensão e aceitação;

4-pró-atividade: ser estimulante e excitante, capaz de sugerir uma ação efetiva;

5-facilidade para definição de metas: proporcionar aos tomadores de decisão a facilidade em definir metas para serem alcançadas;

6-consistência cientifica: usar metodologia que sejam cientificamente definidas e de fácil reprodução, além de socialmente aceitável;

7-acessibilidade dos dados: usar informações relativamente fáceis de coletar e utilizar, a um custo acessível;

8-confiabilidade da fonte: usar informações coletadas em fontes confiáveis;

9-amplitude geográfica: ser sensível às mudanças no espaço, podendo considerar escalas locais, regionais ou mesmo globais;

10- padronização: dar referência a procedimentos padronizados, a fim de facilitar comparações com outras situações;

11- sensibilidade a mudanças no tempo: mostrar mudanças ao longo do tempo mostrando suas tendências;

12- adequabilidade a mudanças da realidade: ter facilidade de se ajustar na medida com que novas condições se apresentem;

13- preditividade: avisar antecipadamente sobre os problemas antes que se tornem de difícil solução;

14- capacidade de síntese: transmitir uma mensagem geral, mas possibilitar ao usuário visualizar os detalhes.

Silva (2000) então aduz que para a caracterização dos indicadores de sustentabilidade urbana, "é necessário que se estabeleçam os conceitos, as definições, os objetivos, os critérios e métodos que embasam a sua formulação, as suas escalas espaciais de abrangência e atuação, o perfil dos usuários e formuladores dessas informações e as limitações inerentes ao processo". 


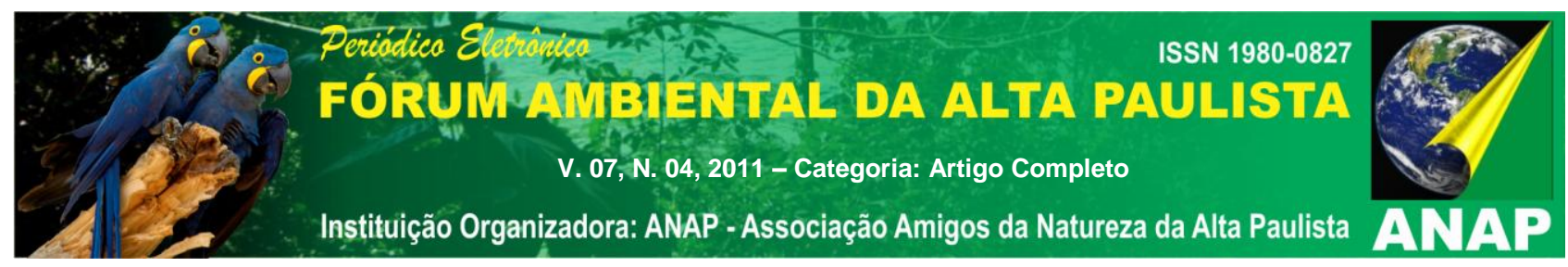

Assim, como diz Silva (2000) "um dos maiores desafios para a compreensão dos Indicadores de Sustentabilidade Urbana reside na busca de uma inserção consistente e objetiva deste instrumental no universo de uma idéia que se encontra em construção e para a qual não se tem definições ou conceitos plenamente estruturados e reconhecidos".

\section{CONCLUSÃO}

Os indicadores econômicos foram durante muito tempo erroneamente utilizados como indicadores de qualidade de vida. Mas, nas últimas décadas, devido à gravidade dos problemas que passaram a colocar em risco as condições de vida no planeta, começaram a surgir ações procurando garantir a boa qualidade de vida para todos.

Mas, para saber se estamos indo no caminho certo da sustentabilidade, é preciso conhecer bem o lugar em que vivemos e acompanhar suas mudanças ao longo do tempo.

Então, a partir da Conferência das Nações Unidas sobre Meio Ambiente e Desenvolvimento (CNUMAD) em 1992, os indicadores de sustentabilidade surgem em vários países abordando os aspectos ambientais, econômicos, sociais, políticos e culturais (dimensões da sustentabilidade). Assim, como instrumento de gestão, os indicadores ajudam a medir ações realizadas no município, avaliando recursos em diferentes aspectos, estabelecendo metas de melhoria e prevendo problemas.

Além de serem utilizados como instrumento de diagnóstico de uma determinada realidade com a finalidade de auxiliar políticas e tomadas de decisões, os indicadores de sustentabilidade também têm uma importante capacidade de aglutinar a participação comunitária, pois podem ser compreendidos por cada indivíduo, mudando a concepção de cada um, e conseqüentemente seus hábitos e costumes.

Portanto, a apresentação de indicadores de sustentabilidade permite verificar a situação do município, para estabelecer a utilização de recursos de uma forma mais sustentável, e conseqüentemente trazer mais qualidade de vida aos seus habitantes.

\section{REFERÊNCIAS}




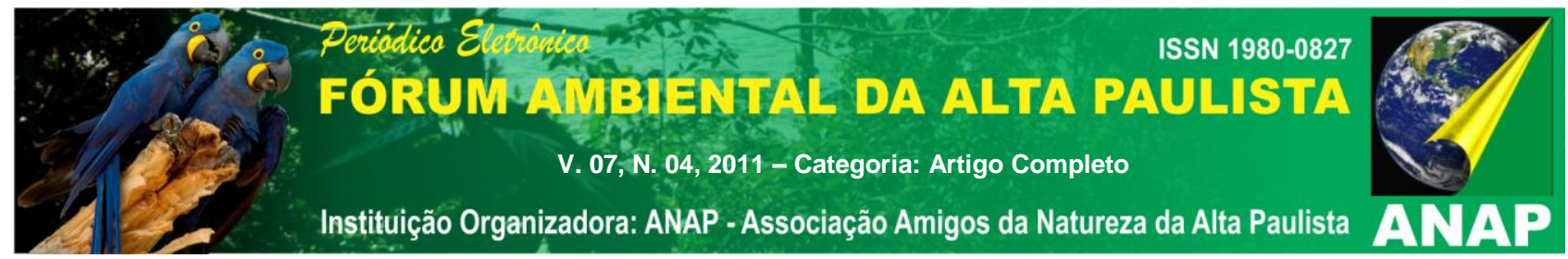

ALMEIDA, Aline Branco de. Sistemas urbanos de água e esgoto: princípios e indicadores de sustentabilidade. 2003. Dissertação (Mestrado em Engenharia Urbana) - Departamento de Engenharia Urbana, Universidade Federal de São Carlos, São Carlos. 2003.

BREMER, Ulisses Franz. Rumo às cidades sustentáveis. Disponível em: <http://www.agirazul.com.br/nat/cidades.htm>. Data de acesso: 03 de dez. 2004.

FIGUEIREDO, Glauco Antônio Bologna Garcia de. Sistemas urbanos de água: avaliação de método para análise de sustentabilidade ambiental de projetos. 2000. Dissertação (Mestrado em Engenharia Urbana) Departamento de Engenharia Urbana, Universidade Federal de São Carlos, São Carlos. 2000.

FREITAS, José Carlos de. O Estatuto da Cidade e o equilíbrio do espaço urbano. Disponível em: <http://www.mp.sp.gov.br>. Data de acesso: 12 de nov. 2004

OLIVEIRA, Isabel Cristina Eiras de. Estatuto da cidade: para aprender. Rio de Janeiro: IBAM/DUMA, 2001.

ORLANDI NETO, Narciso. Regularização do parcelamento do solo. In: FREITAS, José Carlos de (coord.). Temas de Direito Urbanístico 2. São Paulo: CAOHURB, 2000, p. 353-364.

RHEINGANTZ, Eduardo. A megalópole da periferia. Temas de Direito Urbanístico 2. São Paulo:

CAOHURB, 2000, p. 161-167.

ROCHA, Júlio Cesar de Sá da. Considerações jurídicas sobre a função ambiental da cidade. Revista de Direito Ambiental. São Paulo: n. 14, p. 103-112, abril a junho 1999.

ROCHA, Vera Lúcia da. Estudo da estrutura urbana e análise dos problemas ambientais da cidade de Iguape-SP como subsídio ao Plano Diretor do Município. 1999. 84f. Dissertação (Mestrado em Ciência da Engenharia Ambiental) - Crhea/EESC, Universidade de São Paulo, São Carlos. 1999.

SÁ, Elida; BRITO, Isa. O planejamento como instrumento da construção da cidadania. Revista de Direito Ambiental. São Paulo: n. 7, p. 34-53, julho a setembro 1997.

SANTOS, Marcus Vinícius Monteiro dos. Loteamentos irregulares e clandestinos - a improbidade administrativa decorrente da omissão dos agentes públicos no seu dever de fiscalização. In: FREITAS, José Carlos de (coord.). Temas de Direito Urbanístico 2. São Paulo: CAOHURB, 2000, p. 241-253.

SILVA, Sandra Regina Mota. Indicadores de sustentabilidade urbana: as perspectivas e as limitações da operacionalização de um referencial sustentável. 2000. Dissertação (Mestrado em Engenharia Urbana) Departamento de Engenharia Urbana, Universidade Federal de São Carlos, São Carlos. 2000.

--1ndicadores de sustentabilidade urbana. 2000. Disponível em:

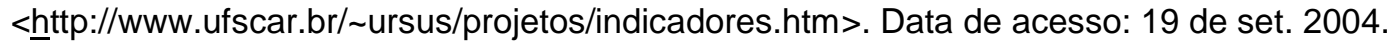

-----. Proposição de princípios básicos para a sustentabilidade. Disponível em: <http://www.ufscar.br/ ursus/projetos/ sustentabilidade.htm>.Data de acesso: 19 de set. 2004.

SOUZA, Marcelo Lopes de. ABC do desenvolvimento urbano. Rio de Janeiro: Bertrand Brasil, 2003. 